\title{
Comparison of Genetic Gains of Agronomical Traits from Different Selection Methods in Soybean
}

\section{Vu Thi Thuy Hang ${ }^{1}$, Vu Dinh Hoa', Le Thi Tuyet Cham ${ }^{1}$, Nguyen Thanh Tuan', Pham Thi Ngoc ${ }^{1}$ and Nguyen Phuong Thao ${ }^{2}$}

${ }^{1}$ Faculty of Agronomy, Vietnam National University of Agriculture, Hanoi 131000, Vietnam

${ }^{2}$ Crop Research and Development Institute, Vietnam National University of Agriculture, Hanoi 131000, Vietnam

\begin{abstract}
This study aimed to compare the genetic gains of two different selection methods for agronomic traits in soybean. A population from the cross of VI045032 x 4904 (LSB 10) was advanced using the bulk method and modified bulk method to the $\mathrm{F}_{6}$ generation. Measured traits were growth duration, plant height, height of the first pod node, number of pods per plant, the percentage of 3-seeded pods, 100-seed weight, individual yield, and yield. Both methods were equally efficient and could be used for segregating and the stabilizing phase of progenies/populations of soybean crosses. However, the bulk method appeared to be more efficient for the improvement of yield-related traits while the modified bulk method was more efficient for the improvement of morphological traits.
\end{abstract}

\section{Keywords}

Bulk method, efficiency, genetic gain, modified bulk method, selection

\section{Introduction}

Soybean (Glycine max (L.) Merr.) breeding, like the breeding of other crops, is a process involving the development of variability for desirable traits, selection of superior genotypes, and multiplication of seeds (Dallastra et al., 2014; Desissa, 2017). Variability is obtained through various methods such as hybridization, mutation, and biotechnology applications. Different selection methods used for the identification of desirable traits are the pedigree, single-seed descent, mass selection, and bulk methods (Allard, 2014). In addition, modified selection methods have also been developed and applied elsewhere (Toledo et al., 1994; Destro et al., 2003; Miladinovic et al., 2011). Progress in plant breeding largely depends on the skill of the breeder in identifying selection criteria 
and applying selection methods that are able to promote the desired changes in characteristics of interest in a breeding program. Very traditional and common selection methods for self-pollinated crops and for soybean, in particular, are pedigree, pure line, bulk, and single seed descent (Acquaah, 2012). Each selection method has both advantages and disadvantages, and their efficiencies depend upon a variety of circumstances. The pedigree and single-seed descent (SSD) method has been used successfully and most often in soybean breeding (Cooper, 1990; Orf, 2008). However, in the bulk selection method, the population is advanced in bulk with no artificial selection until later generations when nearly homozygous lines are selected for yield testing. This makes the bulk method advantageous over those methods used most often.

In addition, various studies have reported variable efficiencies with different and modified methods of selection applied in cross progenies. In studies comparing several generations advancing methods, Toledo et al. (1994) showed that single pod descent (SPD) and single pod descent with selection (SPDS) had similar probabilities in generating descendants with high grain yield when the sample of genetic variability was comparable. Using similar methods, Destro et al. (2003) concluded that both the SPD and SPDS methods were equivalent for the number of days to maturity in the $F_{3}$ generation, and for the number of days to flowering in the $\mathrm{F}_{4}$ generation. However, SPDS was preferable since it yielded superior means for several specific traits such as plant height and individual yield. In a study by Miladinovic et al. (2011), among three methods of selection, modified single seed descent was the most efficient in terms of the improvement of mean values for seed yield and genetic gain compared to the other two methods, modified single-seed descent and the bulk method.

The choice of method depends on the breeding objective, available genetic variability, availability of facilities, application levels of machines, and skills of the breeders. In addition, available information on the efficiencies of various selection methods is significantly useful for soybean breeders in choosing appropriate methods. Thus, this study aims to compare genetic gains of two different selection methods, namely the bulk and modified bulk methods, for morphological and yield-related traits in soybean.

\section{Materials and Methods}

\section{Hybrid generations and selection methods}

A cross between VI045032 x 4904 (LSB10) was made in the spring of 2014. The $F_{1}$ generation was wide-spaced planted in a glasshouse for seed production. Two methods of selection were applied to the hybrid progeny as described below.

\section{Bulk method (Method 1)}

Seeds of the $F_{1}$ hybrid generation were bulked and planted to obtain seeds for the $F_{2}$ generation. Seeds of each $\mathrm{F}_{2}$ plant were harvested separately and planted in rows as families in the $\mathrm{F}_{3}$ generation. In the $\mathrm{F}_{3}$, three seeds of each plant from each family were then harvested and bulked. In the F4 and F5 generations, seeds of each family were planted in rows. Visually, the desirable F5 plants were chosen based on the selection criteria described in the line evaluation methods (Table 1), and seeds from each selected plant were planted in separate rows in the F6 generation to produce 27 lines.

\section{Modified bulk method (Method 2)}

Seeds of the F1 hybrid generation were bulked and planted to obtain seeds for the F2 generation. Seeds of each F2 plant were harvested separately and planted in rows as families for the $\mathrm{F}_{3}$ generation. Visually, five desirable/good $\mathrm{F}_{3}$ plants were selected based on the selection criteria, and seeds of each plant were planted in separate rows in the $F_{4}$ generation. Seeds from each of the $\mathrm{F}_{4}$ lines were harvested and bulked for the $F_{5}$ generation. Visually, good plants in the $F_{5}$ generation were selected and seeds from each were planted in separate rows in the $\mathrm{F}_{6}$ generation to produce 25 lines.

\section{Line evaluation}

The $\mathrm{F}_{6}$ lines were planted in double rows of $3 \mathrm{~m}$ long plots at a spacing of $45 \times 10 \mathrm{~cm}$. The parents were planted with two replications. 
Table 1. Measured traits in the LSB10 families

\begin{tabular}{|c|c|}
\hline Trait & Definition \\
\hline Growth duration & days; number of days from sowing to maturity \\
\hline Plant height & $\mathrm{cm}$; length from ground level to the tip of the main stem \\
\hline Height of the first pod node & $\mathrm{cm}$; length from the ground level to the insertion node of the first pod on the stem \\
\hline Number of pods per plant & number of pods; total number of filled pods per plant \\
\hline Percentage of 3 -seeded pods & $\%$; number of 3-seeded pods/total number of pods per plant \\
\hline 100-seed weight & g; average weight of three sets of 100 seeds \\
\hline Individual yield & $\mathrm{g} /$ plant; seed yield per plant \\
\hline Yield & tons ha ${ }^{-1}$; converting seed yield for each experimental plot to yield in terms of tons per hectare \\
\hline
\end{tabular}

Measured traits included phenology, agronomical traits, and yield-related traits in the $\mathrm{F}_{5}$ and $\mathrm{F}_{6}$ generations to analyze genetic gains (Table 1). Ten plants were randomly taken from each plot for measurements.

The criteria for selection in different generations and the $\mathrm{F}_{6}$ generation were: plant height of $\geq 40 \mathrm{~cm}$, height of first pod node $\geq 10$ $\mathrm{cm}$, individual yield of $\geq 14 \mathrm{~g} / \mathrm{plant}$, and yield of $\geq 2.0$ tons $\mathrm{ha}^{-1}$. Other traits included lodging tolerance, having non-shattering pods, and synchronized ripening.

\section{Data analysis}

Broad sense heritabilities for the traits in the $\mathrm{F}_{5}$ generation were calculated and used for analyzing genetic gains in the $F_{6}$ generation using the following equation (Allard, 2014):

$$
\mathrm{H}^{2}=\left(\mathrm{V}_{\mathrm{P}}-\mathrm{V}_{\mathrm{E}}\right) / \mathrm{V}_{\mathrm{P}}
$$

where, $V_{P}$ is the variance among families and $\mathrm{V}_{\mathrm{E}}$ is the environmental variance.

Genetic advance in absolute unit $(\Delta \mathrm{G})$ and as a percentage of the mean $(\mathrm{GAM})$ in the $\mathrm{F}_{6}$ generation were calculated from the selected $\mathrm{F}_{6}$ families that met the above-mentioned criteria as follows (Johnson et al., 1955):

$$
\Delta \mathrm{G}=\mathrm{R}=\mathrm{SH}^{2} ; \quad \mathrm{GAM}=\Delta \mathrm{G} / \mathrm{X} \times 100
$$

where, $\Delta \mathrm{G}=\mathrm{R}$ is the genetic gain, $\mathrm{S}$ is the selection differential (the difference between the population mean before $\left(X_{P}\right)$ and after $\left(X_{s}\right)$ selection), $\mathrm{H}^{2}$ is the broad sense heritability, and $\mathrm{X}$ is the grand mean.

\section{Results and Discussion}

Means of the measured traits in the $F_{5}$ generation indicated differences in trait expression between the two methods. Although there was no difference in growth duration, method 2 resulted in higher means for all traits except for the percentage of 3 -seeded pods which had a higher mean value in method 1 than in method 2 (7.6 compared to 5.8) as shown in Table 2. Heritability estimates in the LSB10 population were in the range of 0.06-0.70 which were similar to the ranges of other published studies (Rose et al., 1992; Costa et al., 2008; Bilyeu et al., 2010; Desissa, 2017).

Between the two methods, the heritability estimates were quite similar for plant height $(0.68$ and 0.70$)$ and individual yield $(0.23$ and 0.31). Significant differences in the heritability estimates between the two methods were observed for other traits such as the height of the first pod node, percentage of 3-seeded pods, and weight of 100 seeds. Similarly, Miladinovic et al. (2011) estimated different heritabilities for yield, number of pods per plant, number of seeds per plant, and weight of 1000 seeds from bulk, pedigree, and single-seed-descent selection methods in soybean.

The growth duration of the $\mathrm{F}_{6}$ families selected by method 1 was in the range of 94-104 days, which was within the range of the parents (93-105 days) (Table 3). This range was also similar for method 2 (94-107 days) (Table 4). Higher averages for most traits were achieved by families selected using method 2, namely plant height, height of the first pod node, the total number of pods/plant, individual yield, and yield.

The $\mathrm{F}_{6}$ families expressed good growth with average plant heights $>45 \mathrm{~cm}$. Several of the families had plant height exceeding $70 \mathrm{~cm}$, such as LSB10-15, LSB10-2-14, LSB10-3-6, and LSB10-4-11. However, plants that were can be susceptible to lodging. 
Table 2. Means and broad sense heritabilities for measured traits in the $F_{5}$ generation of the LSB10 population for the two selection methods

\begin{tabular}{|c|c|c|c|c|}
\hline \multirow{2}{*}{ Traits } & \multicolumn{2}{|l|}{ Method 1} & \multicolumn{2}{|l|}{ Method 2} \\
\hline & Means of families $(X p)$ & $\mathrm{H}^{2}$ & Means of families (Xp) & $\mathrm{H}^{2}$ \\
\hline Growth duration (days) & 90.0 & & 90.0 & \\
\hline Plant height $(\mathrm{cm})$ & 17.9 & 0.68 & 18.3 & 0.70 \\
\hline Height of the first pod node $(\mathrm{cm})$ & 4.9 & 0.11 & 8.3 & 0.44 \\
\hline Number of pods per plant & 18.4 & 0.57 & 75.8 & 0.14 \\
\hline Percentage of 3-seeded pods (\%) & 7.6 & 0.52 & 5.8 & 0.06 \\
\hline 100-seed weight $(\mathrm{g})$ & 20.2 & 0.11 & 26.1 & 0.46 \\
\hline Individual yield (g/plant) & 7.0 & 0.23 & 12.7 & 0.31 \\
\hline
\end{tabular}

The overall numbers of pods per plant were quite variable from 20.6-56.0 pods/plant for both methods. The 100 -seed weight of the $\mathrm{F}_{6}$ families were classified into light $(<10 \mathrm{~g} / 100$ seeds), medium (10-17 g/100 seeds), and heavy (>17 g/100 seeds) groups. Method 1 seemed to produce slightly larger 100 -seed weight than method 2.

Individual yield ranged from 7.2-14.5 g/plant and 9.2-19.8 g/plant in methods 1 and 2, respectively. There were several families with high individual yields ( $\geq 14 \mathrm{~g} /$ plant) selected from both methods, such as LSB10-3, LSB10-7, LSB10-16, LSB10-3-11, LSB10-17-1, and LSB10-33-7.

The highest average yield for the $F_{6}$ families selected by method 1, 2.06 tons $\mathrm{ha}^{-1}$, was achieved by LSB10-11, while that of the $\mathrm{F}_{6}$ families selected by method 2, 2.58 tons ha $^{-1}$ was achieved by LSB10-33-7 which was also higher than the parents. The numbers of families with yields $\geq 2$ tons ha $^{-1}$ were 5 and 12 for methods 1 and 2, respectively.

Based on the selection criteria, 5 families were selected using method 1 (LSB10-7, LSB10-8, LSB10-11, LSB10-16, and LSB1022) and 10 families were selected using method 2 (LSB10-1-16, LSB10-3-4, LSB10-3-11, LSB10-4-19, LSB10-12-2, LSB10-14-18, LSB10-15-10, LSB10-17-1, LSB10-22-10, and LSB10-33-7). These families were used for the genetic gain calculation (Table 5).

Although trait expressions in method 2 seemed to be better than in method 1 , genetic gains showed the opposite trend. Method 1 produced higher genetic gain values for yieldrelated traits such as a total number of pods per plant, the percentage of 3-seeded pods, 100-seed weight, and individual yield. In contrast, method 2 yielded higher genetic gain values for plant height and height of the first pod node (Table 5). Among the measured traits, the highest gains from both selection methods were for plant height.

When comparing the efficiencies of three different selection methods in soybean, Miladinovic et al. (2011) found that the pedigree, single-seed descent, and bulk methods produced various genetic gain values depending on the traits and populations. For example, the pedigree method resulted in a higher genetic gain for seed yield and number of pods per plant while single seed descent had the highest genetic gain values for 100-seed weight. Even in another crop, faba bean, Ahmed et al. (2008) suggested that the pedigree selection method was the best for breeding for higher yield compared to the mass selection and picking-pod methods.

Genetic advances as percentages of the means were classified as low $(0-10 \%)$, moderate (10-20\%), and high (above 20\%) as stated by Johnson et al. (1955) and Zaraf et al. (2008). Thus, plant height, number of pods per plant, and percentage of 3 -seeded pods obtained high genetic advances in method 1. In method 2, only plant height had high a genetic advance (51.8). Thus, high heritabilities for the plant height, number of pods per plant, and percentage of 3seeded pods were associated with high genetic advances, indicating additive gene action in the inheritance of these traits. 
Table 3. Means of the measured traits for the LSB10 families selected in the $F_{6}$ generation by the bulk method $(\operatorname{method} 1)$

\begin{tabular}{|c|c|c|c|c|c|c|c|c|}
\hline $\begin{array}{l}\text { Families/ } \\
\text { Parents }\end{array}$ & $\begin{array}{c}\text { Growth } \\
\text { duration } \\
\text { (days) }\end{array}$ & $\begin{array}{l}\text { Plant } \\
\text { height } \\
(\mathrm{cm})\end{array}$ & $\begin{array}{l}\text { Height of the } \\
\text { first pod } \\
\text { node }(\mathrm{cm})\end{array}$ & $\begin{array}{l}\text { Number of } \\
\text { pods per } \\
\text { plant }\end{array}$ & $\begin{array}{l}\text { Percentage of 3- } \\
\text { seeded pods (\%) }\end{array}$ & $\begin{array}{l}100 \text {-seed } \\
\text { weight }(\mathrm{g})\end{array}$ & $\begin{array}{l}\text { Individual } \\
\text { yield } \\
\text { (g/plant) }\end{array}$ & $\begin{array}{c}\text { Yield } \\
\text { tons } \mathrm{ha}^{-1} \text { ) }\end{array}$ \\
\hline LSB10-1 & 103 & 50.9 & 12.2 & 40.8 & 18.8 & 17.7 & 13.7 & 1.87 \\
\hline LSB10-2 & 100 & 56.2 & 11.1 & 23.0 & 25.9 & 21.4 & 9.7 & 1.97 \\
\hline LSB10-3 & 102 & 59.5 & 12.9 & 41.9 & 18.2 & 17.0 & 14.0 & 1.78 \\
\hline LSB10-4 & 99 & 63.2 & 12.2 & 42.9 & 18.4 & 16.0 & 13.6 & 1.85 \\
\hline LSB10-6 & 98 & 62.6 & 11.1 & 27.8 & 16.2 & 17.7 & 9.2 & 1.11 \\
\hline LSB10-7 & 99 & 56.0 & 11.5 & 44.0 & 17.8 & 18.0 & 14.5 & 2.04 \\
\hline LSB10-8 & 99 & 59.7 & 12.3 & 41.6 & 18.7 & 18.2 & 14.1 & 2.00 \\
\hline LSB10-9 & 94 & 50.7 & 9.7 & 30.8 & 24.6 & 18.9 & 11.5 & 1.14 \\
\hline LSB10-11 & 100 & 56.3 & 13.0 & 41.1 & 19.0 & 18.2 & 14.2 & 2.06 \\
\hline LSB10-12 & 98 & 51.1 & 10.3 & 30.4 & 28.3 & 18.4 & 10.8 & 1.02 \\
\hline LSB10-13 & 94 & 52.8 & 10.8 & 28.6 & 16.6 & 19.8 & 10.7 & 1.79 \\
\hline LSB10-14 & 99 & 55.6 & 10.8 & 41.3 & 17.9 & 17.8 & 14.2 & 1.85 \\
\hline LSB10-15 & 102 & 71.6 & 11.7 & 43.5 & 17.6 & 16.6 & 14.2 & 1.78 \\
\hline LSB10-16 & 101 & 57.9 & 12.2 & 42.3 & 18.7 & 17.5 & 14.1 & 2.01 \\
\hline LSB10-17 & 98 & 48.8 & 12.4 & 44.6 & 18.0 & 17.9 & 14.3 & 1.98 \\
\hline LSB10-18 & 94 & 55.0 & 9.8 & 29.5 & 20.7 & 21.0 & 11.9 & 0.84 \\
\hline LSB10-19 & 98 & 51.0 & 9.8 & 20.6 & 25.2 & 21.5 & 8.3 & 1.98 \\
\hline LSB10-20 & 101 & 52.6 & 10.4 & 34.3 & 17.0 & 18.0 & 11.9 & 0.95 \\
\hline LSB10-22 & 100 & 59.0 & 11.0 & 43.7 & 18.5 & 17.2 & 14.1 & 2.01 \\
\hline LSB10-24 & 98 & 53.0 & 11.3 & 27.6 & 14.6 & 16.3 & 8.8 & 1.89 \\
\hline LSB10-25 & 100 & 52.7 & 9.4 & 31.0 & 17.7 & 19.0 & 11.5 & 1.58 \\
\hline LSB10-27 & 98 & 46.8 & 9.8 & 33.9 & 18.4 & 17.3 & 10.8 & 1.65 \\
\hline LSB10-28 & 101 & 68.6 & 11.4 & 42.2 & 21.7 & 16.3 & 13.7 & 1.84 \\
\hline LSB10-29 & 104 & 59.2 & 9.1 & 25.6 & 15.2 & 15.4 & 7.2 & 1.78 \\
\hline LSB10-31 & 98 & 50.7 & 10.0 & 28.5 & 21.3 & 20.8 & 11.4 & 1.23 \\
\hline LSB10-32 & 98 & 54.0 & 11.8 & 24.4 & 16.3 & 18.1 & 8.7 & 1.87 \\
\hline LSB10-34 & 94 & 50.4 & 10.0 & 39.8 & 21.4 & 16.9 & 13.3 & 1.07 \\
\hline VI045032 & 105 & 68.5 & 12.0 & 44.3 & 18.5 & 18.2 & 15.6 & 1.87 \\
\hline 4904 & 93 & 71.4 & 11.4 & 41.5 & 19.3 & 17.0 & 13.8 & 1.97 \\
\hline Min & 94 & 46.8 & 9.1 & 20.6 & 14.6 & 15.4 & 7.2 & 0.84 \\
\hline Max & 104 & 71.6 & 13.0 & 44.6 & 28.3 & 21.5 & 14.5 & 2.06 \\
\hline Average & 98.9 & 55.8 & 11.0 & 35.0 & 19.4 & 18.1 & 12.0 & 1.66 \\
\hline $\operatorname{LSD}_{0.05}$ & 3.1 & 2.4 & 0.6 & 1.6 & 1.3 & 0.9 & 0.6 & 3.1 \\
\hline
\end{tabular}


A practical and efficient method for the micropropagation of japanese cherry (Prunus sp.)

Table 4. Means of the measured traits for the LSB10 families selected in the $F_{6}$ generation by the modified bulk method (method 2)

\begin{tabular}{|c|c|c|c|c|c|c|c|c|}
\hline $\begin{array}{l}\text { Families/ } \\
\text { Parents }\end{array}$ & $\begin{array}{c}\text { Growth } \\
\text { duration } \\
\text { (days) }\end{array}$ & $\begin{array}{l}\text { Plant height } \\
\text { (cm) }\end{array}$ & $\begin{array}{l}\text { Height of } \\
\text { the first pod } \\
\text { node }(\mathrm{cm})\end{array}$ & $\begin{array}{l}\text { Number of } \\
\text { pods/ plant }\end{array}$ & $\begin{array}{c}\text { Percentage } \\
\text { of 3-seeded } \\
\text { pods }(\%)\end{array}$ & $\begin{array}{l}100 \text {-seed } \\
\text { weight }(\mathrm{g})\end{array}$ & $\begin{array}{l}\text { Individual } \\
\text { yield } \\
\text { (g/plant) }\end{array}$ & $\begin{array}{c}\text { Yield } \\
\left(\text { tons ha }^{-1}\right)\end{array}$ \\
\hline LSB10-1-16 & 100 & 66.2 & 12.7 & 44.3 & 16.8 & 16.9 & 14.2 & 2.09 \\
\hline LSB10-2-14 & 98 & 72.4 & 12.7 & 42.2 & 18.3 & 16.7 & 13.9 & 2.14 \\
\hline LSB10-3-4 & 101 & 57.4 & 12.0 & 45.8 & 17.7 & 15.6 & 14.3 & 2.05 \\
\hline LSB10-3-6 & 100 & 71.8 & 11.8 & 40.7 & 19.4 & 17.2 & 13.7 & 1.87 \\
\hline LSB10-3-11 & 100 & 63.3 & 10.6 & 44.0 & 28.7 & 19.5 & 17.3 & 2.05 \\
\hline LSB10-4-11 & 102 & 78.9 & 12.2 & 44.2 & 17.9 & 16.2 & 13.9 & 1.89 \\
\hline LSB10-4-19 & 103 & 74.2 & 13.1 & 42.5 & 17.6 & 15.4 & 14.6 & 2.19 \\
\hline LSB10-12-2 & 100 & 73.3 & 12.0 & 46.8 & 16.1 & 17.1 & 14.1 & 2.26 \\
\hline LSB10-13-22 & 99 & 67.5 & 12.3 & 43.6 & 18.3 & 16.6 & 13.8 & 1.93 \\
\hline LSB10-14-18 & 107 & 72.5 & 13.2 & 42.3 & 16.7 & 17.3 & 14.3 & 2.07 \\
\hline LSB10-15-6 & 100 & 69.6 & 13.8 & 41.6 & 18.8 & 17.1 & 13.8 & 1.80 \\
\hline LSB10-15-8 & 104 & 60.4 & 11.4 & 38.0 & 21.2 & 14.1 & 10.7 & 1.05 \\
\hline LSB10-15-10 & 99 & 73.9 & 12.3 & 40.6 & 18.7 & 18.0 & 14.3 & 2.07 \\
\hline LSB10-15-17 & 104 & 60.9 & 9.9 & 33.0 & 25.3 & 21.4 & 14.3 & 1.74 \\
\hline LSB10-15-20 & 101 & 72.2 & 11.7 & 45.0 & 19.0 & 16.0 & 14.0 & 1.91 \\
\hline LSB10-16-20 & 101 & 69.8 & 12.7 & 39.7 & 19.9 & 17.9 & 13.9 & 2.12 \\
\hline LSB10-17-1 & 100 & 74.0 & 12.5 & 45.1 & 18.9 & 18.6 & 16.0 & 2.20 \\
\hline LSB10-22-5 & 100 & 63.6 & 12.2 & 25.0 & 16.8 & 18.8 & 9.2 & 1.98 \\
\hline LSB10-22-10 & 101 & 75.0 & 12.5 & 43.5 & 18.2 & 16.6 & 14.0 & 2.10 \\
\hline LSB10-22-11 & 101 & 57.6 & 12.4 & 26.0 & 18.0 & 19.6 & 9.8 & 0.84 \\
\hline LSB10-28-10 & 102 & 71.3 & 13.0 & 43.9 & 17.7 & 15.9 & 13.6 & 1.97 \\
\hline LSB10-28-21 & 104 & 69.3 & 12.9 & 45.0 & 26.7 & 17.3 & 16.2 & 1.92 \\
\hline LSB10-30-13 & 104 & 66.5 & 10.8 & 40.0 & 23.5 & 13.1 & 10.6 & 0.80 \\
\hline LSB10-31-16 & 104 & 54.0 & 12.0 & 28.0 & 18.4 & 18.7 & 10.0 & 1.10 \\
\hline LSB10-33-7 & 94 & 71.1 & 11.7 & 56.0 & 24.3 & 17.2 & 19.8 & 2.58 \\
\hline VI045032 & 105 & 68.5 & 12.0 & 44.3 & 18.5 & 18.2 & 15.6 & 1.94 \\
\hline 4904 & 93 & 71.4 & 11.4 & 41.5 & 19.3 & 17.0 & 13.8 & 2.07 \\
\hline Min & 94 & 54.0 & 9.9 & 25.0 & 16.1 & 13.1 & 9.2 & 0.80 \\
\hline Max & 107 & 78.9 & 13.8 & 56.0 & 28.7 & 21.4 & 19.8 & 2.58 \\
\hline Average & 101.2 & 68.3 & 12.2 & 41.1 & 19.7 & 17.2 & 13.8 & 1.87 \\
\hline $\operatorname{LSD}_{0.05}$ & 3.1 & 2.4 & 0.6 & 1.6 & 1.3 & 0.9 & 0.6 & 3.1 \\
\hline
\end{tabular}

The results indicated that a change in the mean value of a population did not always reflect the actual status of the mean values for the measured traits. In this study, the selection method that brought about a higher mean value for a given trait was not always be the method that achieved a higher genetic gain in relation to the previous generation. It had been expected that the highest genetic gains would be correlated with the highest mean values for given traits. However, in this study, the higher gains were more frequently found in families selected using method 1 rather than method 2. It was also noticed that method 1 was more efficient in improving genetic gains for yield-related traits such as the number of pods per plant, 100-seed weight, and individual yield. By contrast, method 2 was more efficient for morphological improvement. 
Table 5. Comparison of genetic gains in the measured traits for the $F_{6}$ generation of LSB10 families selected by the two methods

\begin{tabular}{|c|c|c|c|c|c|c|c|c|}
\hline \multirow[b]{2}{*}{ Trait } & \multicolumn{4}{|c|}{ Method 1} & \multicolumn{4}{|c|}{ Method 2} \\
\hline & $\begin{array}{c}\text { Mean of } F_{5} \\
\text { families }(X p)\end{array}$ & $\begin{array}{c}\text { Means of } \\
\text { selected } F_{6} \\
\text { families }(X s)\end{array}$ & $\Delta \mathrm{G}$ & GAM & $\begin{array}{c}\text { Mean of } F_{5} \\
\text { families (Xp) }\end{array}$ & $\begin{array}{c}\text { Means of } \\
\text { selected } F_{6} \\
\text { families }(X s)\end{array}$ & $\Delta G$ & GAM \\
\hline Growth duration (days) & 90 & 99.8 & - & - & 90 & 100.5 & - & - \\
\hline Plant height $(\mathrm{cm})$ & 17.9 & 57.8 & 27.1 & 46.9 & 18.3 & 70.1 & 36.3 & 51.8 \\
\hline $\begin{array}{l}\text { Height of the first pod } \\
\text { node }(\mathrm{cm})\end{array}$ & 4.9 & 12.0 & 0.8 & 6.7 & 8.3 & 12.3 & 1.7 & 13.8 \\
\hline $\begin{array}{l}\text { Number of pods per } \\
\text { plant }\end{array}$ & 18.4 & 42.5 & 13.8 & 32.5 & 75.8 & 45.1 & -4.3 & -9.5 \\
\hline $\begin{array}{l}\text { Percentage of 3- } \\
\text { seeded pods (\%) }\end{array}$ & 7.6 & 18.5 & 5.7 & 30.8 & 5.8 & 19.4 & 0.8 & 4.1 \\
\hline 100-seed weight (g) & 20.2 & 17.8 & -0.3 & -1.7 & 26.1 & 17.2 & -4.1 & -23.8 \\
\hline $\begin{array}{l}\text { Individual yield } \\
\text { (g/plant) }\end{array}$ & 7.0 & 14.2 & 1.7 & 12.0 & 12.7 & 15.3 & 0.8 & 5.2 \\
\hline
\end{tabular}

Note: $\triangle G$ : Genetic gain; GAM: Genetic advance as a percentage of the mean.

\section{Conclusions}

Both the bulk and modified bulk methods are efficient and allow breeders to select and advance desirable plants. In addition, different selection methods should be used based on breeding objectives. The bulk method is more efficient in improving yield-related traits while the modified bulk method is more efficient in improving morphological traits.

\section{Acknowledgements}

The authors would like to acknowledge the funding from Vietnam National University of Agriculture, Vietnam during the period of 20162018, which greatly contributed to the completion of this work.

\section{References}

Acquaah G. (2012). Principles of plant genetics. John Wiley \& Sons, Ltd. 740 pages.

Allard R. W. (2014). Principles of plant breeding. Wiley India Pvt Ltd. 484 pages.

Ahmed M. S. H., Abd-El-Haleem S. H. M., Bakheit M. A. and Mohamed S. M. S (2008). Comparison of three selection methods for yield and components of three faba bean (Vicia faba L.) crosses. World Journal of Agricultural Sciences. Vol 4. pp. 635-639.

Bilyeu K., Ratnaparkhe M. B. and Kole C. (2010). Genetics, genomics and breeding of soybean. CRC Press, USA.
Cooper R. L. (1990) Modified early generation testing procedure for yield selection in soybean. Crop Science. Vol 30. pp. 417-419.

Costa M. M., Di Mauro A. O., Unêda-Trevisoli S. H., Arriel N. H. C., Bárbaro I. M., Silveira G. D. and Muniz F. R. S. (2008). Heritability estimation in early generations of two-way crosses in soybean. Bragantia. Vol 67. pp. 101-108.

Dallastra A., Unêda-Trevisoli S. H., Ferraudo A. S. and Mauro A. O. D. (2014). Multivariate approach in the selection of superior soybean progeny which carry the RR gene1. Revista Ciência Agronômica. Vol 45. pp. 588-597.

Desissa D. H. (2017). Genetic variability, heritability and genetic advances of soybean (Glycine max (L.) Merrill) varieties grown at Bako Tibe in Western Ethiopia. Asian Journal of Plant Science and Research. Vol 7. pp. 20-26.

Destro D., Bizeti H. S., Garcia L. A., de Batista Fonseca I. C., Montalván R. and Miglioranza E. (2003). Comparison between the SPD and the SPDS methods for segregating generation advancement in soybean. Brazilian Archives of Biology and Technology. Vol 46. pp. 545-551.

Johnson H. W., Robinson H. F. and Comstock R. E. (1955). Estimates of genetic and environmental variability in Soybean. Agronomy Journal. Vol 47. pp. 314-318.

Miladinovic J., Burton J. W., Tubic S. B., Miladinovic D., Djordjevic V. and Djukic V. (2011). Soybean breeding: comparison of the efficiency of different selection methods. Turkish Journal of Agriculture and Forestry. Vol 35. pp. 469-480.

Orf J. H. (2008) Methods of soybean breeding. In: Miladinovic J., Hrustic M. and Vidic M. (Ed). Soybean. AMB Grafi ka, Novi Sad. pp. 176-194. 
Rose J. L., Butler D. G. and Ryley M. J. (1992). Yield improvement in soybeans using recurrent selection. Australian Journal of Agricultural Research. Vol 43. doi: 10.1071/AR9920135.

Toledo J. F. F., Almeida L. A., Kiihl R. A. S., CarrãoPanizzi M. C., Kaster M., Miranda L. C. and Menosso O. G. (1994). Genetics and breeding. In: Tropical
Soybean: Improvement and Production. Food Agriculture Organization of the United Nations, Rome. pp. 19-36.

Zaraf I., Arshad M., Ashiraf M., Nacem R. and Malik M. F. (2008). Genetic divergence and correlation studies in soybean (Glycine max (L.) Merrill) genotypes. Pakistan Journal of Botany. Vol 42. pp. 971-976. 